\title{
UPTAKE OF A FEW DIVALENT HEAVY-METAL ION SPECIES FROM THEIR AQUEOUS SOLUTIONS BY CORAL SAND HEAT-TREATED AT VARIOUS TEMPERATURES
}

\author{
YOSHITAKE SUZUKI* AND YASUSHI TAKEUCHI \\ Department of Industrial Chemistry, Meiji University, Kawasaki 214
}

Key Words: Adsorption, Aragonite, Calcite, Coral Sand, Heavy-Metal ions Removal, Hysteresis, Ion Exchange

\begin{abstract}
Mechanism and equilibrium relationships for the uptake of $\mathrm{Cd}^{2+}, \mathrm{Cu}^{2+}$ and $\mathrm{Pb}^{2+}$ by coral sand from their nitrate aqueous solutions were studied.

The maximum amounts of $\mathrm{Pb}^{2+}$ and $\mathrm{Cd}^{2+}$ uptaken by coral sand dried at $403 \mathrm{~K}$ were about 1.3 and 0.9 mol $\cdot \mathrm{kg}^{-1}$, respectively. That of $\mathrm{Cu}^{2+}$ was only about $1 / 100$ that of $\mathrm{Pb}^{2+}$ at $\mathrm{pH}=6.1-5.5$. Equilibrium relationships between the concentrations of those ionic species and the amounts uptaken were expressed by either the Langmuir or the Freundlich isotherm.

The amounts of those ions uptaken and the physical properties of the coral sand varied with the maximum temperature during treatment. For example, the B.E.T. specific surface area decreased with increasing heattreatment temperature. This is due to the change in the crystallographic structure of calcium carbonate, which is the main component of the coral sand, from aragonite to calcite.
\end{abstract}

\section{Introduction}

Following the death of coral, which grows in clean, warm seawater, organic substances in its body are decomposed by biological degradation. Vestiges of loopholes in the body of the coral remain as pores and inorganic flame cells form a substrate. The inorganic flame cells will be the broken by ocean current into small pieces or granules like sand. These granules, which accumulate on the sea bottom, are called "coral sand" as a generic name, though they include some granules originating from other substrates such as shells. Also, according to its origin, granules of the coral sand may consist of a dominant chemical compound, calcium carbonate, and small amounts of other impurities.

It is known that some divalent metal ions can be uptaken by coral sand ${ }^{5)}$, and aragonite, one of the crystal forms of calcium carbonate, in coral sand is easily transformed to calcite under a certain condition ${ }^{12)}$. These facts were confirmed by previous work on the physical and chemical properties of coral sand ${ }^{10)}$.

In this work, the behavior of the uptake of divalent ions by a coral sand was studied, focusing on the effect of heat treatment and quantitative analysis to clarify the equilibrium relationships.

\section{Experimental}

\subsection{Material used and its properties}

The raw material used was so-called coral sand granules obtained on the coast of Okinawa Island. Since the granules were contaminated with salts, they were

\footnotetext{
* Received February 12, 1993. Correspondence concerning this article should be addressed to Y. Suzuki.
}

washed with tap water until the so-called harshness of the surfaces disappeared. They were then washed by demineralized water until no chloride ion was detected in the remaining water. Then they were dried at 300-306 $\mathrm{K}$ by exposure to sunshine in summer or at $303 \mathrm{~K}$ in an incubator (Constant Temperature Oven, Model 2-2135 made by Isuzu Seisakusho Co., Ltd.) until their weight became constant. Thus obtained sample of coral sand is called Sample A.

The chemical composition of Sample A was analyzed by an atomic absorption spectrometric method and is listed in Table 1. When a coral grows in a certain sea bottom, seasonal change in temperature of the seawater causes a cyclic variation of chemical composition in the direction of the growth of coral bodies. One cycle corresponds to a year, and usually the coral grows about $1.2 \times$ $10^{-2} \mathrm{~m}$ in a year. Therefore, the composition of coral sand is not uniform in its growth direction. Since coral sand is a mixture of granules into which so-called fossil coral has been broken, however, its macroscopic chemical composition is almost uniform.

The granules of the sample are almost all beige or light brown color, but a part of them is ruddy. Also, they are relatively brittle and a part of them can be broken even during sieving. Their forms are different from one another, as shown in Fig. 1.

The size distribution of Sample A, shown in Fig. 2, indicates that their particle sizes, taken as the geometric mean of the smaller and the larger projective lengths of granules, are mostly $0.2-1.0 \times 10^{-3} \mathrm{~m}$. In the present work, the particles were sieved and a fraction of $250-$ $840 \times 10^{-6} \mathrm{~m}(250$ to $840 \mu$ sieve after JIS $)$ range was 
Table 1. Main chemical composition of coral sand (Sample A)

\begin{tabular}{|c|c|c|c|c|}
\hline Element & $\mathrm{Ca}$ & $\mathrm{Mg}$ & $\mathrm{Sr}$ & $\mathrm{Si}$ \\
\hline [wt $\%]$ & 44.5 & 2.17 & 0.32 & 0.25 \\
\hline \multicolumn{5}{|c|}{$\begin{array}{l}\text { Other components contained were } \mathrm{S}, \mathrm{Na}, \mathrm{K}, \mathrm{P}, \mathrm{Al}, \mathrm{Os}, \mathrm{Ru} \text { and } \mathrm{Er} \text {, but the } \\
\text { sum of these components was less than } 0.4 \mathrm{wt} \% \text {. The amount of } \mathrm{CO}_{3} \text {, } \\
\text { estimated from } \mathrm{CO}_{2} \text { emitted, was } 51.3 \mathrm{wt} \% \text {. The amout of insoluble residue } \\
1.02 \mathrm{wt} \% \text {. }\end{array}$} \\
\hline
\end{tabular}

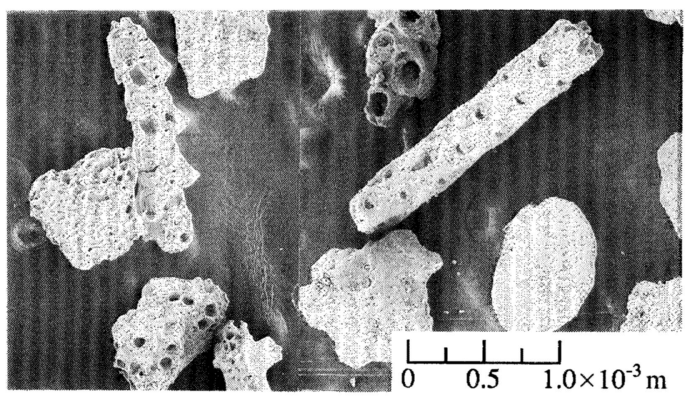

Fig. 1 Various shapes of Sample A granules

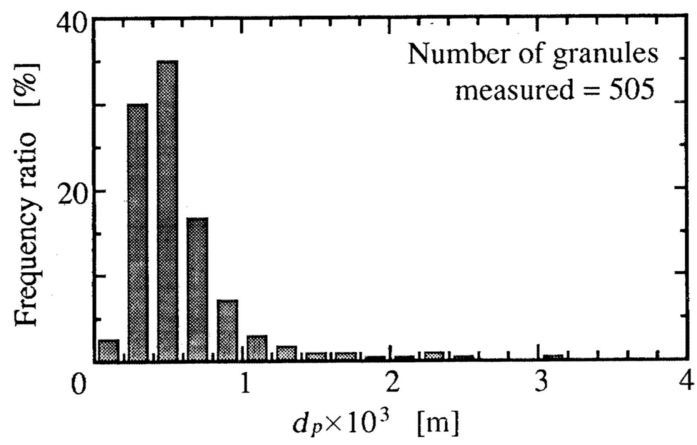

Fig. 2 Particle size distribution of Sample A granules

used in most cases. The geometric mean diameter of the fraction was $4.58 \times 10^{-4} \mathrm{~m}$.

The coral sand is relatively porous, as shown in Fig. 3, due to its origin. The B.E.T. specific surface area was $8.0 \times 10^{2} \mathrm{~m}^{2} \cdot \mathrm{kg}^{-1}$ and the pore volume was $1.8 \times 10^{-4}$ $\mathrm{m}^{3} \cdot \mathrm{kg}^{-1}$ by a nitrogen adsorption method (Equipment used was Bel Sorp 28 from Bel Japan, Inc.) and $2.7 \times 10^{-4}$ $\mathrm{m}^{3} \cdot \mathrm{kg}^{-1}$ by a mercury porosimeter (Micrometrics Pore Sizer 9320, Shimadzu Co.), respectively.

Adsorption and desorption isotherms for nitrogen at liquid nitrogen temperature are shown in Fig. 4. When the relative pressure $\left(P / P_{s}\right)$ was larger than about 0.45 there appeared a particular hysteresis loop between two lines, suggesting that Sample A had slit-shaped pores after De Boer and Custers ${ }^{2,3)}$ or narrow pores with relatively smaller meso-pore volume ${ }^{1)}$ such as that of Norit BRX.

The pore size distributions of the sample determined by nitrogen adsorption and mercury porosimetry are shown in Fig. 5. In the results obtained by the latter method, sudden sawtooth changes were observed probably due to breakage of particles. This suggests that the pores in Sample A may be almost macropores according

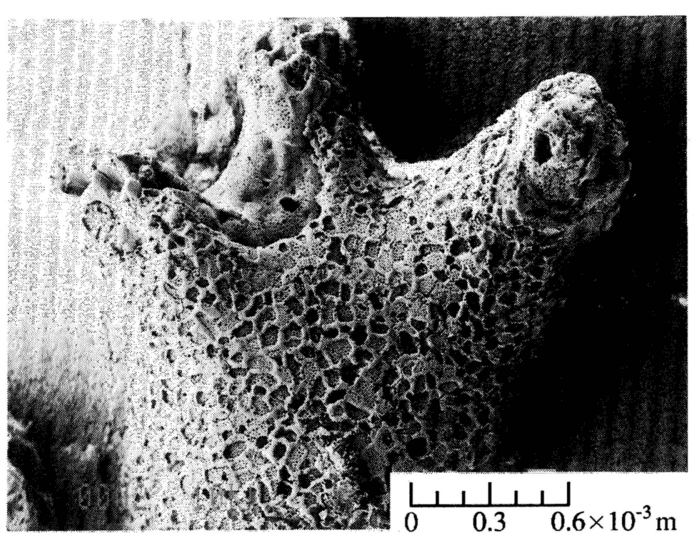

Fig. 3 An example of the surface of Sample A

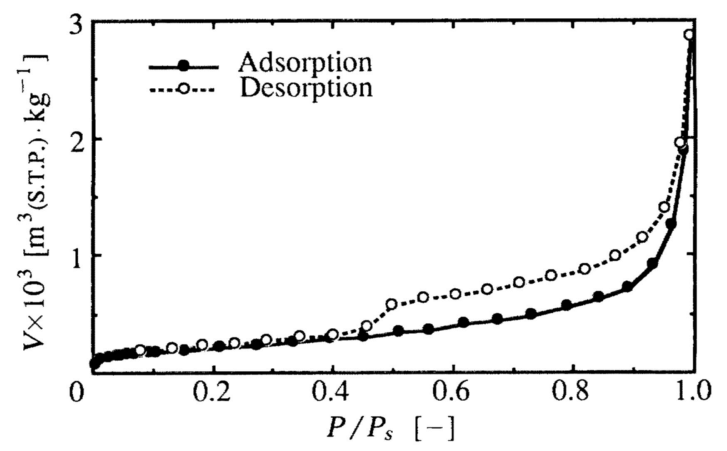

Fig. 4 Adsorption isotherms for nitrogen - Sample A at $77 \mathrm{~K}$

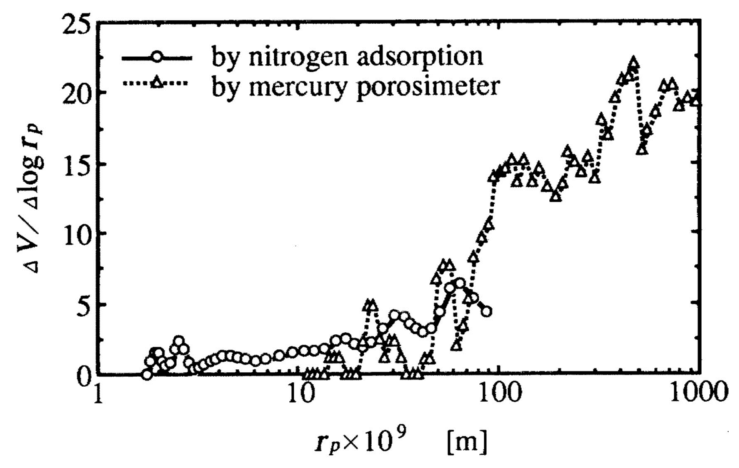

Fig. 5 Pore size distribution of Sample A

to a classification after the IUPAC Manual of Symbols and Terminology4), though there exists a small amount of mesopore.

The crystal forms of calcium carbonate in Sample A granules were measured by an X-ray diffractometer (Rigaku Co. Ltd., RINT 1200 with a $\mathrm{Cu}$ X-ray tube (voltage and current were $40 \mathrm{kV}$ and $20 \mathrm{~mA}$, respectively) and a graphite monochrometer). The diffraction pattern obtained was analyzed by two methods: the multiple analytical line method $^{7)}$ and the pattern fitting method $^{6)}$. The calcite form was about $60 \mathrm{wt} \%$ in the granules, and the aragonite form was determined to be about $25 \mathrm{wt} \%$. The rest of the material might be classified as amorphous calcium carbonate.

The true density of Sample A was found to be 2.75 $\times 10^{3} \mathrm{~kg} \cdot \mathrm{m}^{-3}$, which seems reasonable since it reflects 
Table 2. Conditions of drying and heat treatment

\begin{tabular}{ccc}
\hline Sample & Temperature $[\mathrm{K}]$ & Time $[\mathrm{h}]$ \\
\hline A & 303 & 48 \\
B & 403 & 24 \\
C & 523 & 2.0 \\
D & 673 & 1.0 \\
E & 1073 & 0.30 \\
\hline
\end{tabular}

Each sample was treated under atmospheric pressure in air

the abundance ratio of two crystallographic forms, i.e., the density of calcite form: $2.71 \times 10^{3} \mathrm{~kg} \cdot \mathrm{m}^{-3}$, and that of aragonite form: $2.93 \times 10^{3} \mathrm{~kg} \cdot \mathrm{m}^{-3}{ }^{8}$ ). From the examination of the density, the volume per granule and the volumetric shape factor (=6.(volume per granule)/ $\left.\left.(\pi \cdot \text { (average value of diameters of granules })^{3}\right)\right)$ were calculated to be $5.2 \times 10^{-11} \mathrm{~m}^{3} \cdot(\text { a granule })^{-1}$ and 0.30 , respectively.

\subsection{Divalent heavy metal ions used}

Aqueous solutions of various concentrations of three divalent heavy metal ions, i.e., $\mathrm{Cd}^{2+}, \mathrm{Cu}^{2+}$ and $\mathrm{Pb}^{2+}$, were prepared from their nitrate salts. The $\mathrm{pH}$ values of the solutions were not particularly controlled, and the values were measured simply by a $\mathrm{pH}$ meter (F13 from Horiba Co., Ltd.). Concentrations of the metal ions and the calcium ion eluted were determined by a polarized Zeeman atomic absorption spectrophotometer (Hitachi, Ltd., Z-6000).

\subsection{Experimental procedure}

1) Heat treatment Sample A granules were divided into four portions. Each portion was heated under the conditions shown in Table 2. An electric crucible furnace from Isuzu Seisakusho Co., Ltd., Model RR-14N was used, except for treatment of Sample B.

First, one of the samples was put into a lidless crucible (PSA 4-C made of high purity alumina ceramics, $0.052 \mathrm{~m}$ in external diameter and $0.067 \mathrm{~m}$ in height). The crucible was placed in the furnace and a lid was placed on the furnace, leaving a small opening. The crucible, containing Sample A particles, was heated at a rate of about $30 \mathrm{deg} \cdot \mathrm{min}^{-1}$ up to $523 \mathrm{~K}$. Heating was continued at that temperature for 2 hours, after which the crucible was removed from the furnace and cooled in a desiccator. The sample thus obtained was named Sample C.

Two other samples, D and E, were prepared in the same way as Sample C, at $673 \mathrm{~K}$ and $1073 \mathrm{~K}$, respectively.

The measurement and monitoring of the temperature of the crucible were performed by use of an alumelchromel thermocouple and an indicating pyrometer (CAA-1 and CG-2 by Isuzu Seisakusho Co., Ltd., respectively).

Sample B was obtained simply by heat treatment at $403 \mathrm{~K}$ in the incubator.

2) Measurement of the equilibrium amount uptaken Aqueous solutions of a nitrate salt of divalent heavy metals were mixed with a predetermined amount of each

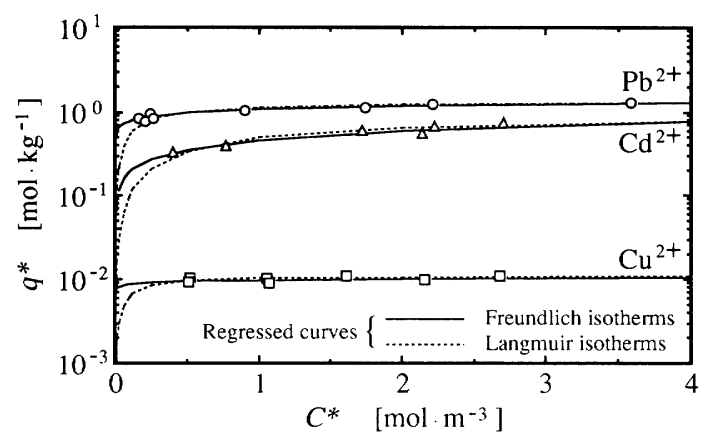

Fig. 6 Equilibria for uptake of three divalent heavy metal ionic species by coral sand Sample B at $298.2 \mathrm{~K}$

Table 3. Equilibrium constants ( $\mathrm{M}^{2+}$ - Sample B, at 298.2 $\mathrm{K})$

\begin{tabular}{clccc}
\hline Species of ion & \multicolumn{1}{c}{$k^{*}$} & $n[-]$ & $K\left[\mathrm{~m}^{3} \cdot \mathrm{mol}^{-1}\right]$ & $q_{\infty}\left[\mathrm{mol} \cdot \mathrm{kg}^{-1}\right]$ \\
\hline $\mathrm{Cu}^{2+}$ & 0.00978 & 18.6 & 11.9 & 0.0111 \\
$\mathrm{Cd}^{2+}$ & 0.455 & 2.60 & 1.13 & 0.926 \\
$\mathrm{~Pb}^{2+}$ & 1.09 & 7.07 & 6.37 & 1.33 \\
\hline
\end{tabular}

* Unit of $k:\left[\mathrm{mol}^{(\mathrm{n}-1) / \mathrm{n}} \cdot \mathrm{m}^{-3 / \mathrm{n}} \cdot \mathrm{kg}^{-1}\right]$

sample, and the resulting mixtures were kept at $298.2 \mathrm{~K}$ in a thermostat shaker. The concentrations of each ion before mixing and after reaching equilibrium were measured by the atomic absorption spectrophotometer.

From the mass balance for each ion, such as the following equation, the amounts uptaken were calculated.

$$
q^{*}=V \cdot\left(C_{0}-C^{*}\right) / m
$$

where $V$ is the volume of aqueous solution, $m$ is the weight of sample granules and $C$ and $q$ indicate the concentrations of each ion in the solution and the amount of ion uptaken, respectively. At the same time, the values of $\mathrm{pH}$ and the concentrations of calcium eluted were analyzed.

\section{Results and Discussion}

\subsection{Equilibrium relationship of each ion for Sample} B

The relationships between the concentrations and the amounts of each ionic species uptaken by each sample at equilibrium could be correlated either by the Freundlich isotherm or by the Langmuir isotherm, as shown in Fig. 6 for $\mathrm{Pb}^{2+}, \mathrm{Cd}^{2+}$ and $\mathrm{Cu}^{2+}$, respectively. Then the values of two constants, $k$ and $n$, in the Freundlich equation (Eq. (2)),

$$
q^{*}=k C^{* 1 / n}
$$

and $K$ and $q_{\infty}$ in the Langmuir equation (Eq. (3)),

$$
q^{*}=K q_{\infty} C^{*} /\left(1+K C^{*}\right)
$$

were obtained by regression of data, as listed in Table 3 . The amounts of ions uptaken at a certain equilibrium 


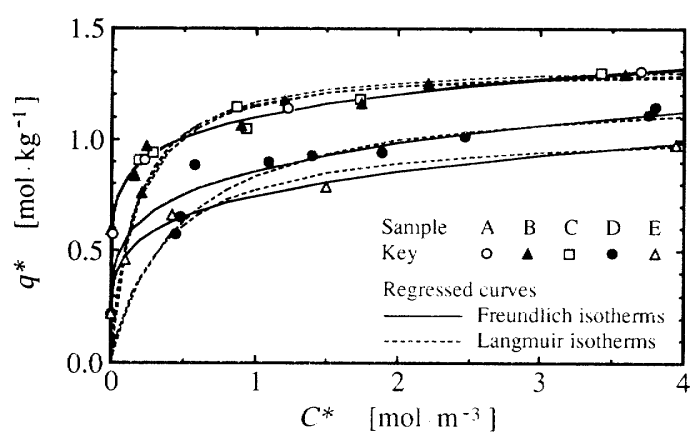

Fig. 7 Equilibria for uptake of $\mathrm{Pb}^{2+}$ by samples heat-treated at various temperatures (298.2 K)

Table 4. Equilibrium constants $\left(\mathrm{Pb}^{2+}\right.$ - Sample A to $\mathrm{E}$ systems, at $298.2 \mathrm{~K}$ )

\begin{tabular}{cccccc}
\hline \multicolumn{2}{c}{ Sample (Temp. $\left.{ }^{*}[\mathrm{~K}]\right)$} & $k^{* *}$ & $n[-]$ & $K\left[\mathrm{~m}^{3} \cdot \mathrm{mol}^{-1}\right]$ & $q_{\infty}\left[\mathrm{mol} \cdot \mathrm{kg}^{-1}\right]$ \\
\hline A & $(303)$ & 1.10 & 7.59 & 6.05 & 1.31 \\
B & $(403)$ & 1.10 & 7.63 & 6.38 & 1.33 \\
C & $(523)$ & 1.10 & 7.51 & 5.86 & 1.34 \\
D & $(673)$ & 0.857 & 5.11 & 2.10 & 1.23 \\
E & $(1073)$ & 0.745 & 5.05 & 2.75 & 1.06 \\
\hline
\end{tabular}

*Temp.: Heat-treatment temperature, ${ }^{* *}$ Unit of $k:\left[\mathrm{mol}^{(\mathrm{n}-1) / \mathrm{n}} \cdot \mathrm{m}^{-3 / \mathrm{n}} \cdot \mathrm{kg}^{-1}\right]$

concentration, $q^{*}$, were always in the order $\mathrm{Cu}^{2+}, \mathrm{Cd}^{2+}$ and $\mathrm{Pb}^{2+}$. The order was the same as that for the values of enthalpy change of hydration ${ }^{9)}$, though the ionic radius of $\mathrm{Ca}^{2+}$ is smaller than that of $\mathrm{Pb}^{2+}$ and larger than those of $\mathrm{Cu}^{2+}$ and $\mathrm{Cd}^{2+}$. Since each heavy metal ion is generally associated with water molecules, each is liberated from water molecules to exchange with $\mathrm{Ca}^{2+}$ ions that exist at the substrate surface, as follows.

$$
\begin{aligned}
\mathrm{M}^{2+} \cdot\left(\mathrm{H}_{2} \mathrm{O}\right)_{\mathrm{n}} & \rightarrow \mathrm{M}^{2+}+\mathrm{n} \mathrm{H}_{2} \mathrm{O} \\
\mathrm{M}^{2+}+\text { C.S. } C a & \rightleftarrows \text { C.S. }-\mathrm{M}+\mathrm{Ca}^{2+}
\end{aligned}
$$

where $\mathrm{M}^{2+}$ denotes the divalent heavy metal ions and C.S. means the substrate of coral sand granules. It seems that the ease of ion exchange is in inverse proportion to the magnitude of energy necessary to separate water molecules from ions rather than the ionic size, and that the values of hydration enthalpy for each ionic species are suitable to predict the uptake. However, the large difference between the amounts of $\mathrm{Cu}^{2+}$ and $\mathrm{Pb}^{2+}$ uptaken cannot be explained on that basis, because their enthalpies are only $7 \%$ smaller and $32 \%$ larger respectively than that of $\mathrm{Ca}^{2+}$. Therefore, the real reason for such difference as above seems to lie elsewhere, for example in the difference of stabilities of these ions in solutions and in crystals formed by ion exchange.

The uptake of $p$-nitrophenol was then examined for Sample B. The relationship between the concentrations and the amount uptaken was expressed by the following linear isotherm.

$$
\begin{aligned}
& q^{*}=3.82 \times 10^{-3} C^{*} \\
& \left(C^{*}<0.2 \mathrm{~mol} \cdot \mathrm{m}^{-3}, 9.1<\mathrm{pH} \text { at equilibrium }<9.4\right)
\end{aligned}
$$

The amount uptaken was much smaller than that of

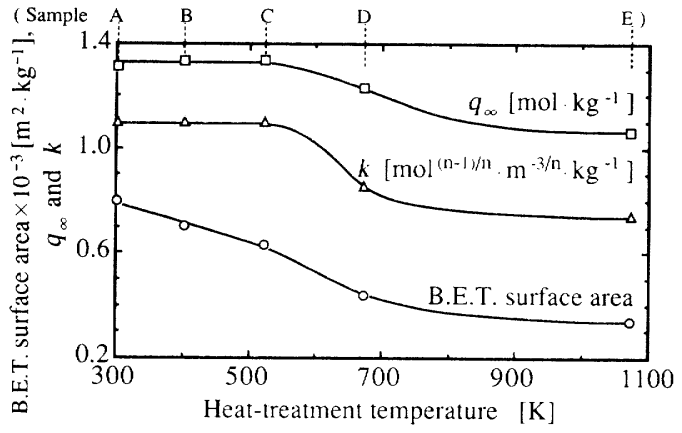

Fig. 8 Variation of B.E.T. specific surface area and equilibrium constants ( $q_{\infty}$ in Langmuir eq. and $k$ in Freundlich eq., at $298.2 \mathrm{~K}$ ) for $\mathrm{Pb}^{2+}$ with temperature

metal ions, i.e., $\mathrm{Cu}^{2+}$ uptaken and $\mathrm{Ca}^{2+}$ eluted. Also, in the region of $9.1<\mathrm{pH}<9.4, p$-nitrophenol seemed to exist as a molecule in the adsorbed phase ${ }^{9)}$, though it existed as an anionic species in the aqueous solution. Therefore, the uptake seems to be caused by adsorption in this case.

\subsection{Equilibrium relationship for each sample and the aqueous $\mathrm{Pb}^{2+}$ solution system}

$\mathrm{Pb}^{2+}$ was well uptaken in Sample B. Its uptake and that of other samples was measured and the results are shown in Fig. 7.

The amounts of $\mathrm{Pb}^{2+}$ uptaken by Samples $\mathrm{A}$ and $\mathrm{C}$ were almost the same as that for Sample B, and the equilibrium relationships were expressed by either Eq. (3) or (4), as before. However, for Samples D and E, which were heat-treated to $673 \mathrm{~K}$ and $1073 \mathrm{~K}$, respectively, the amount of $\mathrm{Pb}^{2+}$ uptaken was smaller than those of Samples $A$ and $B$ under the same equilibrium concentrations, and the value for Sample E was smaller than that for Sample D.

The equilibrium constants for each case are listed in Table 4. Variation in a Langmuir constant, $q_{\infty}$, and a Freundlich constant, $k$, for $\mathrm{Pb}^{2+}$ with heat treatment temperature is shown in Fig. 8. In the figure, variation of B.E.T. specific surface area with heat-treatment temperature is also shown. It is clear that the values of $q_{\infty}$ and $k$ vary in almost the same manner as the surface area up to $523 \mathrm{~K}$, and that their values decreased quickly at some temperature between $523 \mathrm{~K}$ and $673 \mathrm{~K}$.

On the other hand, the B.E.T. specific surface area decreased smoothly, and thus seems not to be the predominant factor of determining the uptake of $\mathrm{Pb}^{2+}$.

In a series of samples obtained by heat treatment of Sample A, it was found that a relatively large change in the values of $q_{\infty}$ and $k$ corresponded with those of the abundance ratio of crystal forms of calcium carbonate in the samples. In other words, the abundance ratio of crystal form varied with temperature, as shown in Fig. 9. The ratio of calcite form was about $60 \mathrm{wt} \%$ for each sample heat-treated under $523 \mathrm{~K}$, though the values calculated by two analytical methods from the X-ray diffraction pattern for each sample showed a small difference. Also, the values for the samples heat-treated 


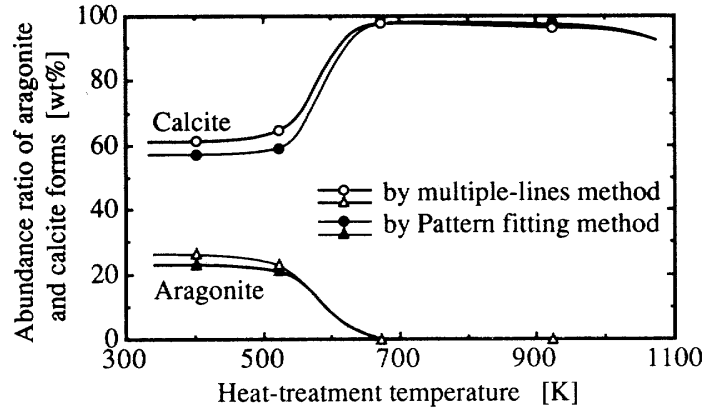

Fig. 9 Variation of abundance ratio of two crystal forms for calcium carbonate with temperature

at $673 \mathrm{~K}$ and $1073 \mathrm{~K}$ were 96 to $98 \mathrm{wt} \%$. On the other hand, the existence of aragonite-form crystal was not confirmed for Samples D and E. Samples B and C showed the ratio of aragonite-form crystal to be about 23 $w t \%$. For Sample E, a small amount of calcium oxide formed by thermal decomposition of calcium carbonate was detected. This was also suggested by observation of surfaces of the sample with a scanning electron microscope.

The temperature range that gives a large change in the equilibrium constants $q_{\infty}$ and $k$ corresponded to that in the weight ratio of each crystal form. Therefore, it is clear that the calcium carbonate of aragonite form uptakes well $\mathrm{Pb}^{2+}$ from the aqueous solution, and the maximum amount uptaken $\left(q_{\infty}\right)$ will be about 1.7 mol $\cdot \mathrm{kg}^{-1}$ provided the amount uptaken by an amorphous form of calcium carbonate is almost the same as that uptaken by aragonite. On the contrary, the value for calcite was about $1.1 \mathrm{~mol} \cdot \mathrm{kg}^{-1}$, a value corresponding to 65 wt $\%$ of the value for the aragonite form, according to the results shown in Fig. 9 and Table 4.

Variation of the equilibrium constants in Samples D and $\mathrm{E}$ cannot be explained simply by the difference in their crystal forms, because the weight ratio of each crystal form does not change. Such difference is caused by other reasons. It may be attributed to the variation in the surface area and the shapes or even the change in pore structures of the samples. Though the values of B.E.T. specific surface area provide a rough estimation of the adsorption capacity, the surface area may not explain the difference in amount uptaken by Samples D and E because the ionic size of $\mathrm{Pb}^{2+}$ is much larger than that of nitrogen molecules. On the other hand, as suggested by the hysteresis loop in nitrogen adsorption and desorption curves, the shapes of pores of Sample A seemed to be the so-called slit type, and they seemed to be the same for Samples B and C. Hysteresis was hardly found for Sample E. Sample D showed a loop whose magnitude was between those of Samples C and E, as shown in Fig. 10. It was considered, therefore, that the pores of socalled slit type decreased and that cracks of visible size were generated with the growth of calcite crystal when the sample granules were heated above $523 \mathrm{~K}$.

From these observations it is thought that the change in amount of $\mathrm{Pb}^{2+}$ uptaken by the heat-treated

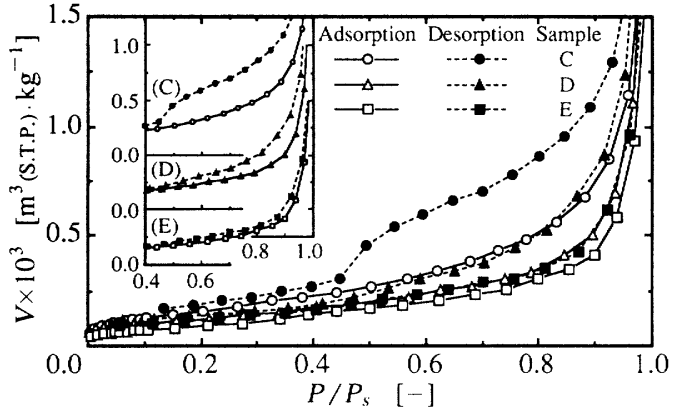

Fig. 10 Variation of hysteresis loops in nitrogen gas adsorption for three samples $(77 \mathrm{~K})$

coral sand granules has two causes. One is the decrease in the ratio of aragonite crystal and the increase of calcite form, and the other is the growth of crystals with decreasing pores.

\section{Conclusion}

Natural coral sand granules were heat-treated at various temperatures and used for the uptake of $\mathrm{Pb}^{2+}$ and other divalent heavy-metal ion species. The amount of $\mathrm{Pb}^{2+}$ uptaken by samples heat-treated below $523 \mathrm{~K}$ was about $1.3 \mathrm{~mol} \cdot \mathrm{kg}^{-1}$. The values for samples obtained by heat treatment above $523 \mathrm{~K}$ became smaller, the minimum value being about $1.1 \mathrm{~mol} \cdot \mathrm{kg}^{-1}$ for the sample treated to $1073 \mathrm{~K}$.

There might be two main reasons for the differences in amount of uptake. One is the decrease in amount of aragonite-form crystals and the increase of calcite-form crystals. The other lies in the growth of the crystal and the resulting decrease in pore volume.

Sample B, obtained by simple drying at $403 \mathrm{~K}$, was subjected to uptake of $\mathrm{Cu}^{2+}$ and $\mathrm{Cd}^{2+}$ as well as $\mathrm{Pb}^{2+}$. The maximum amount of $\mathrm{Cd}^{2+}$ uptaken was about $70 \%$ of that for $\mathrm{Pb}^{2+}$ and that for $\mathrm{Cu}^{2+}$ was about $0.8 \%$. This may be due to the difference in the values of hydration enthalpy, which indicates the energy needed to liberate the metal ionic species from water molecules associated as ligands.

\section{Acknowledgement}

The authors express their deepest thanks to Prof. T. Nakamura of Meiji University for providing X-ray diffraction analysis results. They also thank Messrs Y. Kawashima, Y. Tanaka, H. Haijima and T. Takada for their assistance in experimental works. A part of this study was supported by Coral Biotech Co., Ltd. The authors would like to express their sincere thanks to Mr. S. Asai of that company for his valuable information.

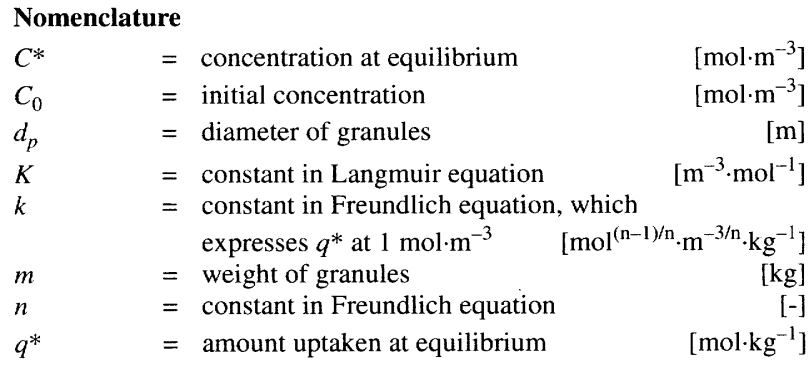


$=$ constant in Langmuir equation that expresses the maximum amount uptaken $\quad\left[\mathrm{mol} \cdot \mathrm{kg}^{-1}\right]$

$\rho_{p}$

V

$\Delta H$ $=$ pore radius

$=$ volume of aqueous solution

$=$ enthalpy change due to hydration

Literature Cited

1) Boehm, H.P., A. Vass and R. Kollmar: Ed. by K.K. Unger, J. Rouquerol, K.S.W. Sing and H. Kral et al., Studies in Surface Science and Catalysis 39, Characterization of Porous Solids, 163172, Elsevier Science Publishers B.V., Amsterdam (1988)

2) De Boer, J.H. and J.F.H. Custers: Z. Phys. Chem. B., 25, 225 (1934)

3) Everett, D.H.: Ed. by K.K. Unger, J. Rouquerol, K.S. W. Sing and H. Kral et al., Studies in Surface Science and Catalysis 39, Characterization of Porous Solids, 1-20, Elsevier Science Publishers B.V., Amsterdam (1988)
4) "IUPAC Manual of Symbols and Terminology", Appendix 2, Part 1, Colloid and Surface Chemistry, Pure and Appl. Chem., 31, 578 (1972)

5) Kitano, Y., N. Kanamori and S. Yoshioka: Geochem. J., 10, 175179 (1976)

6) Matsushita, M. and T. Nakamura, Proc. of 40th annual meeting of Jpn. Soc. for Anal. Chem., 3K22, 530 (1991)

7) Nakamura, T., T. Kodama and M.Ishihara: Analyst, 113, 1737 1741 (1988)

8) Shida, M.: "Kagaku-Jiten“, Ed., 50 and 1178, Morikita-syuppan, Tokyo (1981)

9) Suzuki, Y. and Y. Takeuchi: J. Chem. Eng., Japan., 19, 307-311 (1986)

10) Takeuchi, Y. and Y. Suzuki: Preprint of 3rd Annual Meeting of The Japan Society on Adsorption, 28-29 (1989)

11) The Chem. Soc. of Jpn.: "Kagaku-Benran, Kiso-Hen II", 3rd Ed., 297, Maruzen, Tokyo (1984)

12) Yoshioka, S. and Y. Kitano: Geochem. J., 19, 245-249 (1985) 